\title{
Application of supply chain approach to improving hazard-resilient health services: framework analysis for ASEAN and options of implementation
}

\author{
Minquan $\mathrm{Liu}^{1} \cdot$ Venkatachalam Anbumozhi ${ }^{2}$
}

Accepted: 23 November 2020 / Published online: 6 January 2021

(c) Institute for Social and Economic Change 2021

\begin{abstract}
Infectious diseases such as SARS and COVID-19, like other natural hazards, underline the interconnectedness of the countries. Both manufacturing and services sectors in the economies of Asia have outsourced supplies from different countries in order to gain a competitive advantage through effective value chain management. The motivations for this outsourcing are to achieve technological innovations, reduce end-product prices, and strengthen strategic competitiveness. This paper applies a supply chain approach to develop the concept of a hazard-resilient healthcare system (HRHS) and to explore ways how this might be achieved. After reviewing the current international thinking on HRHS, which has narrowly focused on building national capacities with national capabilities, it argues that a supply chain approach may provide a better, more robust, and in many ways more realistic, approach to enhance the hazard resilience of national healthcare systems. Within such an approach, capabilities of the local actors (local health authorities and healthcare providers) in a pandemic or disaster-prone situation remain important and should be further strengthened, but international support and assistance in times of emergency should also be a key plank of the system. In a changing world with more frequent high-impact pandemics and disasters, such international support need not be one way, but both ways. A system of mutual support may be developed by forming an effective international common pool of capability in responding to the health needs when a major disaster occurs anywhere in a region or globally. Even though serious limitations exist in the current thinking on HRHS, significant progress has been made on the international humanitarian assistance front, especially in the ASEAN region. While developments on this front have not been a part of the purview of the current international thinking on HRHS, it is argued that they may well form an important corner stone in a typical future national HRHS.
\end{abstract}

Keywords Supply chain of healthcare services · Hazard-resilient healthcare system • International humanitarian assistance $\cdot$ Disaster and pandemic response capability

The authors wish to thank two anonymous referees for helpful comments and suggestions which were valuable in the final revision of the paper. Naturally, all remaining errors are the authors' responsibility alone.

Minquan Liu

minquanliu@pku.edu.cn

Extended author information available on the last page of the article 
It doesn't matter how big, how rich or how prepared you are, there may be a time when you will need the international community to support you in your relief and recovery efforts. International Federation of Red Cross And Red Crescent Societies ${ }^{1}$.6 June 2015.

\section{Introduction}

Natural hazards, including epidemics and pandemics, have been a frequent and regular threat to the mankind throughout the history. Most recently, the year 2020 has seen the spread and intensification of the pandemic COVID-19-the most serious since the influenza outbreak in 1918-in most countries in the world, resulting in untold numbers of deaths and necessitating stringent lockdowns. These lockdowns have further interacted with regional and global production networks and supply chains to cause massive impacts on the economies and welfare of the nations.

One of the most affected regions is the Asia-Pacific region. In general, this region, and in particular East and Southeast Asia, is especially prone to a variety of natural hazards (Anbumozhi et al. 2020). On the other hand, this is also a region where growth of crossborder supply chains has been among the fastest in the world in the past several decades (Anbumozhi and Kimura 2020).

However, rather than studying the likely impact of various biological and non-biological disaster events on the normal functioning of production and supply chains, this paper applies a supply chain approach to develop the concept of a hazard-resilient healthcare system and to explore ways how this might be achieved, with a view to reducing the direct human impact of natural disasters. ${ }^{2}$ Such an undertaking means that not only will there be a shift in attention from products to services, there is also going to be a shift in focus away from the economic impact of a disaster to its health impact. After all, disasters are first and foremost events that involve acute losses of human lives, injuries, diseases and other human sufferings. ${ }^{3}$

This shift in focus from economic to health consequences of hazards and disasters ties in well with the recent international moves to reshape the international disaster risk reduction and management agenda. While "Disasters must be considered primarily in terms of their health consequences" (Brenna 2015), ${ }^{4}$ and therefore any agenda to address their consequences must first and foremost be in terms of actions to reduce their health consequence, the actual internationally led approach had, in fact, been rather different. The first internationally endorsed agenda for disaster risk reduction and management - the Hyogo Framework for Action 2005-2015-had actually almost entirely left the need for

\footnotetext{
1 https://reliefweb.int/report/world/asia-pacific-countries-prepare-future-disasters.

2 While the same analysis in this paper would apply to events that have an anthropogenic origin, namely human-caused disasters, the more frequent and devastating events occurring in the world are natural events owing their origins to the working of the nature. In this paper, we are predominantly concerned with these natural events or disasters.

${ }^{3}$ Disasters are actually defined first and foremost in terms of human losses, in particular the number of deaths, injuries, etc. In the case of EMDAT, the most widely available and used international data set on disasters and impacts, criteria for inclusion of an event in the database are: $\geq 10$ people killed, and/or $\geq 100$ people reported affected, and/or a declaration of a state of emergency, and/or a call for international assistance. See Tschoegl et al. (2006).

${ }^{4}$ Richard Brennan was director of emergency risk management and humanitarian response of the World Health Organization at the time.
} 
a comprehensive health response out of the picture, except to recommend the building of hazard-safe hospitals (UNISDR 2006). Subsequent heated international consultations have helped to put the health focus back in, as evidenced by the newly released UN resolution, the Sendai Framework for Action 2015-2030 (UNISDR 2015), where reductions in the health consequences of a disaster and a concept like hazard-resilient health services are explicitly among its key goals.

However, the current international thinking does not seem to be clear-minded as to how these targets are going to be achieved. Only a small body of research has emerged which has gone beyond merely calling for, but also explored ways of helping a country, especially if it is small and resource-wise poor, to build its hazard-resilient healthcare system. Thus, Bennett and Carney (2017) studied the difficulties facing each such country in fulfilling its obligations under the new International Health Regulation as adopted by WHO in 2005, and called for simultaneous efforts at the regional and global level. Liu and Wang (2020) extended the purview to cover all hazards and discussed the role of China in helping build up the international resilience. In respect of ASEAN countries, a report was submitted to ERIA by one of the present authors making broadly similar arguments with recommendations (Liu 2016).

The present paper builds on that literature and explores how developing countries may jointly build up international capabilities to critically improve the hazard resilience of each of their healthcare systems. Section "Hazard-resilient healthcare system as a supply chain of emergency healthcare services" develops the concept of a hazard-resilient healthcare system (HRHS) in terms of a supply chain of services. To be sure, a concept like this has already been in the literature with a rather different take. ${ }^{5}$ In Sect. "The need for and role of international capabilities", we compare the merits and demerits of the alternative approaches and perspectives, arguing that the supply chain-informed approach, emphasizing as it does the international linkages, represents a better, more robust, and in some ways more realistic, approach to promoting the hazard resilience of national healthcare systems. Section "'Lead Firms" and redundancies: local actors and international players" discusses the respective role of the local actors-local health authority and health service providers-and international players in an effective national and/or sub-national HRHS, while Sect. "International humanitarian assistance as part of health service supply chains" reviews some recent developments on the international humanitarian assistance front, in particular in the ASEAN region. Although those developments could form an important pillar in an effective future HRHS program, they alone would not be adequate. Section "International humanitarian assistance: a review" broadens the discussion to consider the need for better coordinated international health responses and the threat of possibly more frequent high-impact events. A final section concludes the paper.

\section{Hazard-resilient healthcare system as a supply chain of emergency healthcare services}

In applying a supply chain approach to the health sector, the first thing to be clear about is whether or not the underlying point of enquiry is the survival and continued operation of some production and distribution network - a given set of production nodes and

${ }^{5}$ See WHO (2008), WHO (2011), and Mitchell et al. (2013), especially chapter 5. 
distribution links that operate in a coordinated way to produce and supply a given final product to the intended customers-against the odds of certain natural hazards. Such a focus of enquiry would imply a fundamental concern with the interest and well-being of the stakeholders in the network. A more hazard-resilient supply chain is one that can better withstand the risks and impacts of the hazards in question and therefore better protect the interest and well-being of the stakeholders therein. This type of enquiry is fully valid on its own terms and would exactly parallel those pursued in other companion papers of this volume. ${ }^{6}$

However, while this type of enquiry may be appropriate for addressing the case of some other industry or sector, it is not so in relation to health. Here, the really important matters are not about, say, the survival and continued operation of the supply chain of some health or medical product-e.g., a particular pharmaceutical industry-but the continued and, indeed, expanded provision of a full range of healthcare services to the affected population in a disaster situation, typically in the face of huge upsurges in demand for these services. The real challenges following a low-frequency high-intensity disaster are: to be able to take immediate and effective measures to reduce the number of deaths and control the scale of injury and disease; to remove and limit possible new vectors of disease and risk factors that may have been unleashed by the disaster; to maintain the level of services to those who would need the care irrespective of the disaster (e.g., the elderly, the disabled, and those who had already been suffering from various diseases); and to address any possible long-term health impact on the affected population (e.g., psychosocial and mental trauma). The really "big question" to address here, before, during, or after a disaster, concerns each of these challenges, and the range of services required is likely to include the full array of primary, secondary, and tertiary care, including public health, medicine, and psychological and mental counseling and care.

A more hazard-resilient healthcare system is one that provides better protection for the actual and potential victims from a given locality or community in each of the above ways, in relation to any likely hazard that may strike the community or locality. The fundamental interests and well-being to protect through building such a system are those of the actual and potential victims, at least in the first instance.

However, how exactly should one conceptualize and design such a system? Different approaches here are possible. A supply chain-based approach is to model such a system as, indeed, a supply chain for the needed healthcare services, organized on a national, regional and, if need be, even global scale, as actual situations might dictate, just as a typical modern product-type supply chain is.

Typically, a product-type modern supply chain can contain an extensive set of firms, organized on a national, regional, and sometimes global scale, with some of these firms acting as production nodes and others as distribution links (and some as both) in the chain. One or a small subset of these firms act(s) as the lead or focal firm(s). Various versions of supply chain are possible, depending on the role the lead firm plays. At one end of the spectrum, the lead firm may itself own and control a significant number of production nodes, as well as having a total control of product designs and specifications. This is known as a producer-driven supply chain. At the other end, a lead firm may control none of the production nodes, but has a commanding control of product designs and specifications and distribution channels. This is often known as a buyer-driven model.

\footnotetext{
${ }^{6}$ For an up-to-date example of this kind of enquiry, see Wang (2018), and the extensive references therein.
} 
It is unlikely that a disaster-resilient healthcare system, nationally for a country or subnationally for a community or locality, can exactly match either of these polar cases, but clearly someone or some entity in the system has to play the equivalent role of a "lead firm." The entire chain may contain an extensive set of service nodes (especially if one is preparing against some potentially major disaster), each catering for a particular kind or kinds of health needs that could arise in an emergency situation. And depending on the scale over which one is contemplating organizing the system, these service nodes may be across the national, regional or even continental boundaries.

Clearly, if each such component service node is to work in unison and effectively to meet the challenges of real disaster situations, some of which may even be unforeseen, their functions will have to be properly coordinated. Exactly who or which entity could and should play this focal coordinating role in a supply chain-like emergency healthcare system, and what range of service nodes are needed and how they may be coordinated, are questions to which no easy answers are available. Much will depend on the particular situation one expects to encounter, and the particular conditions under which one is likely to encounter them. We will return to some of these issues in the next section. For now, it is quite clear that the supply chain concept provides a rather new approach to thinking about the nature and imperatives of an effective future HRHS — one that gives an expanded framework within which to explore the issues.

\section{The need for and role of international capabilities}

The current international thinking on the nature and imperatives of an effective future HRHS for a country or community has been ad hoc, disjointed, and lacking coherence and realism. Some attention has been paid to building disaster-resilient safe hospitals and facilities, but this is no way close to a system view on the matter. ${ }^{7}$ To the extent that there is a system view, the focus has been very much narrowly placed on strengthening national and sub-national health sector emergency preparedness and response, on the basis of existing institutions and institutional structures in each country and community. The document that succinctly presents this position is WHO (2011). ${ }^{8}$ Some technical guidance has been prepared and provided in this regard by WHO and other related international agencies, but because the task has been rather narrowly conceived, it addresses only a rather narrow set of issues and challenges. To the extent that there is an international dimension, its role is limited to:

\footnotetext{
${ }^{7}$ Calls were made in the Hyogo Framework for Action of 2005 for safe hospitals (UNISDR 2006). This was later followed up by some initiatives led by the World Health Organization (WHO) and a few other agencies. See WHO and UK Health Protection Agency and Partner (2011). A Safe Hospital Index was prepared by WHO (WHO and PAHO 2015) and received endorsement at the World Conference on Disaster Risk Reduction in Sendai, Japan, in March 2015.

8 The UN system, which leads and presides over most of global actions and programs in the world today, including various Disaster Risk Reduction (DRR) programs, adopts a cluster approach, whereby actions and programs falling into a particular field or theme is led by the agency whose expertise and functionality matches that field/theme best, supported by other related agencies. On disaster-related health issues, the responsible agency is WHO, supported by other UN agencies including UNICEF, UNFPA, UNAIDS and UNISDR. See WHO et al. (2015).
} 
1. "establish, promote and foster regional and sub-regional collaboration, as well as interregional cooperation within WHO, including the sharing of experience and expertise for capacity development, in risk-reduction, response and recovery" (WHO 2011, p. 3);

2. "call upon WHO Member States, donors and development cooperation partners to allocate sufficient resources for health emergency and disaster risk-management programmes through international development cooperation, humanitarian appeals, and support for WHO's role in health emergency and disaster risk-management matters" (WHO 2011, p. 3).

3. "Calls on Member States, in the context of the COVID-19 pandemic: to put in place a whole-of-government and whole-of-society response including through implementing a national, cross-sectoral COVID-19 action plan that outlines both immediate and longterm actions, with a view to sustainably strengthening their health system and social care and support systems, and preparedness, surveillance and response capacities, as well as taking into account WHO guidance, according to the national context, engaging with communities and collaborating with relevant stakeholders" (WHO 2020, p. 3)

While adequate funding and closer regional and sub-regional collaboration and interregional cooperation through WHO are indeed important, these cannot be the limits to a full-bodied international dimension.

But can we really be realistic in thinking that an effective national and sub-national HRHS can be achieved through developing the capabilities of each and every country and community in question alone, on the basis of current institutions and institutional structures, even with due technical guidance from the relevant international agencies? This may be a realistic proposition for some countries, but it cannot be for all. To begin with, some countries in the world today are quite small (e.g., those small island States) with populations less than a few million, most of whom living in some urban concentrations. If a hazard like the COVID-19 pandemic, or a major earthquake or a super-typhoon, does strike there, it could well devastate the whole country with everyone in it. It might even knock down its very hospitals and other health facilities, paralyzing the whole national healthcare system, in spite of having steadfastly followed the international guidelines on safe hospitals prior to the event. Further, even if its healthcare system withstood the onslaught, still would it be able really to cope with the huge upsurge in demand for medical and other health services following a major event? Or might such upsurge in demand simply outstretch and overwhelm its capacity? Clearly, in such situations, the country would have to seek for international help and support, not just in terms of funding, but also in terms of the real capabilities of providing the healthcare services. Under the present international setup, this has taken the form of emergency international humanitarian assistance, but without such assistance being factored into the prior design of the national or sub-national healthcare system of a country. Each country is advocated, so to speak, to build its own fully self-reliant HRHS ready for meeting the needs of all disaster situations.

The case above addresses a country with a rather small population living in a small geographical area, which could be entirely overwhelmed by a single major disaster. But even if a country is not too small in population and/or geographical expanse, still a major disaster may paralyze much of that country along with its healthcare system, with demand surges outstretching its service capacity, which is likely to be already severely compromised by the event. It may also need international health assistance in times such as this. Only in the exception of some really very large and resource-rich countries (e.g., USA or China) might 
one contemplate building an effective national HRHS by completely relying on its own resources and capabilities. But these countries are rather few and far between.

It would seem that given the scale of healthcare needs that may arise in the event of a major disaster-perhaps even a catastrophic one-such as COVID-19, which could occur in the future to any country in view of some current trends such as global warming, ${ }^{9}$ no country, except those very large and resource-rich ones, can afford to go it alone in emergency health preparedness, by building a fully self-reliant national or sub-national HRHS to meet the potential post-disaster health challenges, without any recourse to outside capability. If this is so, then why not design and build a HRHS for each country with the international support and contributions, in terms of real service-providing capabilities, explicitly recognized and factored in?

It appears that the focus on each country building its own HRHS, consisting of only the country's own health sector capabilities, ignoring the obvious role that can be played by international capabilities, and the obvious need of a disaster affected country for such outside capabilities, has not been well thought out and thought through. The reason may have to do with the fact that health issues for each country have traditionally been treated as a matter only for that country (or for only some sub-national government within a country where the funding system and governance is so decentralized), with each country being tasked to build its own capabilities, preferably by mobilizing its own resources, and to design its own specific system to meet its evolving health challenges on the basis of these capabilities. Each country, as it were, is unto itself, with some international funding and technical guidance if need be, but without any role for international support in terms of real services and capabilities. While some departures from this model have taken place in recent years, ${ }^{10}$ the current mainstream thinking is still firmly in that old mold. Thus viewed, it seems only too natural that each country is left to rely just on itself-its own capabilities-in building a HRHS that it aspires to. ${ }^{11}$

However, while the each-country-unto-itself approach might be valid in addressing regular healthcare needs, it does not appear to be adequate enough in addressing the needs that may arise in the wake of a major disaster. The most obvious reason is, of course, the aforementioned fact that in the case of some countries, such needs may simply outstretch the capacity of their health sector, especially if the sector is itself heavily degraded by the crisis. Additionally, it is also true that natural disasters can happen to any country, so that international help and assistance in this respect need not be viewed as a one-way flow, but both ways. That is, they can be views as a form of mutual assistance and support, in terms of actual healthcare services and capabilities.

\footnotetext{
${ }^{9}$ The increased frequency of disasters has mostly been associated with hydro-climatological disasters, which many attribute to global warming.

${ }^{10}$ For example, the cross-border recruitment of various health human resources on the supply side of the care, and new trends of health tourism on the demand side.

${ }^{11}$ The area where WHO has been most proactive is the prevention and control of the spread of communicable diseases and epidemics-its traditional area of responsibility. Here, in the last two decades, WHO has been developing and laying down a set of rules for each country to comply with, on a country-by-country basis. Its responsibility has mostly been limited to monitoring and provision of certain technical assistance to individual countries. Little has there been mobilization and deployment, at a regional or global level, of real capabilities to forestall serious outbreaks in the world. See the second edition of the International Health Regulations as adopted by the WHO and its member countries in 2005, and Bennett and Carney (2017).
} 
A system with such mutual help and support as a key plank should be a more costeffective way of building and maintaining an effective HRHS for each and every country. Under such a system, a "common" capability may be developed and deployed internationally whenever and wherever it is needed, so that no country needs to build a capability all by itself that fully matches the level of needs expected following a major disaster (but much of it remains idle otherwise). Moreover, this common capability need not be built as an extra-national standing capacity. It can be made up of some specially designated units from each country. In times of a major disaster occurring anywhere in any country concerned, these units can be mobilized and brought together as a single pool of capability. Otherwise, they can stay and serve in their own countries, subject to periodic joint training and simulation exercises.

Organizing and building a HRHS for each country along this line implies making international support and assistance, in terms of real capabilities, a center piece of the new system. Yet, as noted previously, this is precisely what is missing in the current international thinking on the matter. By viewing the HRHS that one wishes to build as consisting of a supply chain for healthcare services organized not only on a national, but also on a regional and even global scale, a supply chain-based approach can help reverse this.

\section{"Lead Firms" and redundancies: local actors and international players}

Earlier, reference was made to the question who or which entity would be best placed to play the role of a "lead firm" in a national (or sub-national) HRHS, treated as a supply chain of healthcare services to meet the needs of the population in times of a disaster. The task of this "lead firm" would be to design, identify and organize the various service nodes in the chain, assign specific functions to them, and call upon them to execute these functions when the need arises. It was noted that the choice, however, is a difficult one and will depend on the specific emergency health needs that are anticipated, and the particular conditions under which these needs are to be met. However, the role of one subset of entities - the local health authority and local healthcare providers - is especially worth noting.

Clearly, they will have a special role to play. After all, they would be the frontline institutions in any emergency situation, are most likely to provide rapid assessments of the developing needs, and are best positioned to mobilize any surviving local resources and capabilities to launch the first round of rescue, search and relief. Their physical presence in the disaster area, their local knowledge of both the pre-disaster situation and post-disaster conditions, including knowledge of any surviving healthcare capability, post-disaster terrain, and road conditions, all put them in the best position to do these.

On the other hand, as noted, they themselves may be seriously affected by the disaster, with their facilities and capabilities heavily compromised. They may also lack the specialized knowledge and experience in tackling particular emergency situations. In these cases, if they are in fact assigned the key role of organizing and coordinating the rescue and relief efforts, especially if these efforts are on an international scale, they may not live up to the task.

Here, some cross-learning from the current understanding of how best to deal with product-type supply chain disruptions can be useful. In those cases, a widely agreed solution is for the system to contain some key "redundancies," such that if one production node or distribution link fails in a crisis, a second one can rise up, provided that this second one 
is so positioned in advance to play this role. The larger aim is to have a "business continuity plan" such that the entire supply chain does not buckle just because some nodes or links of it are struck by a natural hazard. Redundancy forms a key measure in such a plan.

The term "business continuity plan" is, in fact, already adopted by some in the context of discussing emergency preparedness and hazard-resilient healthcare systems. However, it would seem that a better term to use in such contexts is "service continuity plan," which we adopt below.

For the health sector to maintain and, indeed, to vastly expand the level and range of services in response to the evolving needs following a disaster event, prior planning for key redundancies is a critical measure. Moreover, since the most likely service node in the system facing disruption by a disaster is precisely the local health providers and local health authorities, it looks that a "second line of defense" will have to be erected in any effective service continuity plan. Having such a second line of defense is particularly important if, indeed, the local health authority and healthcare providers are to be assigned the key role of coordinating the rescue and relief efforts following a disaster. In view of the danger that the first line of defense faces, a second line of defense must be put in place ready to play this role.

It needs to be said that by stressing the need for a second line of defense, one is by no means denying the importance of strengthening the first line. Having only the first line of defense may well be adequate for some situations, especially if it is duly strengthened through some suitable enforcement (e.g., the safe hospital program). However, the current emphasis is on constructing an all-hazard-resilient healthcare system, ${ }^{12}$ which must include preparing for some likely major or even catastrophic events. While this emphasis is right and proper, it must be accompanied by effective actions. Having a second line of defense is one such action. It takes care of the danger of the first line of defense collapsing in a major disaster event. For most countries, this is likely to call for strong concerted international action. However, for smaller nations, even an otherwise small disaster event may already necessitate a call for adequate interactional actions.

The advantage of having a strong local health system that better resists all types of hazard event is self-evident. However, in constructing an all-hazard-resilient healthcare system, clearly it will be seriously inadequate if our attention is just focused on constructing a strong, all-hazard-resilient local health system. The goal here is not to substitute international (regional or even global) actions for national ones, but rather to have both. We need both lines of defense in a truly effective HRHS.

\section{International humanitarian assistance as part of health service supply chains}

While the international mainstream thinking on the nature and designs of national HRHS's has firmly remained in its traditional mold, significant progress has been made in recent years in international humanitarian assistance, especially in the ASEAN region. Needless to say, humanitarian assistance in the event of a natural disaster typically contains a strong

\footnotetext{
12 The current emphasis on an all-hazard approach has been motivated by a desire to build a generic capability that can deal with the health consequences of all types of disaster. The interpretation here is somewhat different, in terms of the magnitude of a hazard event. Clearly, "all hazards" must include those major and catastrophic hazard events, too.
} 
health component, often through mobilization of international health capabilities. However, in spite of this, initiatives on this front have been treated as entirely "humanitarian," out of the purview of the mainstream thinking on HRHS. It is as if international assistance in health, in the form of mobilization of real health capabilities, even against the extreme conditions of a disaster, is to be shunned for a country or community, and is not to play any major role in a suitably designed national or sub-national HRHS.

But must humanitarian health assistance remain "humanitarian" only? And why cannot such assistance be closely integrated into an effective future national HRHS? In this section, we briefly review major developments on the international humanitarian front with particular reference to the ASEAN region. In many ways, progress on this front in the ASEAN region has been especially marked in recent years. A review of these developments can help suggest ways of better integrating the two disaster-response tracks, the national health track and international humanitarian assistance track, with a view to constructing a truly effective HRHS for countries and nations. Below, a brief review of the general situation of international humanitarian assistance-the main players, principal tools used and services offered-is provided before turning to the Association of South East Asia Nation (ASEAN), with a short account of the recent progress in this region in building up a region-wide network of humanitarian assistance.

\section{International humanitarian assistance: a review $^{13}$}

International humanitarian assistance to countries and peoples in emergency situations dates back to a time even before the founding of the UN and its various agencies. Today, the oldest and still one of the most active players in the field is the International Red Cross and Red Crescent (RCRC) Movement, which commands 187 National RCRC Societies in the world. While a National RCRC Society mobilizes and provides humanitarian assistance to the victims and affected population in its own country during a disaster, the International Federation of the RCRC Societies (IFRC) coordinates and directs international assistance in support of the National Society, through the mobilization of its vast network of national societies. Emergency health has been a strong component of this assistance.

But the more important international network for providing international humanitarian assistance in time of a natural disaster today is the UN and its related agencies. The main UN agencies with a humanitarian mandate include FAO, IOM, OCHA, UNDP, UNFPA, UNHCR, UN-HABITAT, UNICEF, UN Women, WFP and WHO, and they support disaster responses across a wide range of needs, from shelter, food security, nutrition, health, education and livelihoods, to such services as logistics and telecommunications. This wide range of agencies and the actions they take in responding to different post-disaster needs are coordinated by a set of mechanisms. Without going into detail, suffice it to say that a "cluster" approach is adopted, under which health-related humanitarian assistance is led by WHO, supported by other related agencies, and subject to the overall coordination by a UN Humanitarian Coordinator or, in whose absence, the UN Resident Coordinator in the affected country.

This global-level architecture is further supported at the regional level by various regional intergovernmental organizations and forums, NGOs, and sometimes also the private sector. We will review some of these arrangements and recent advances in the context

${ }^{13}$ This and the next subsection draw heavily on OCHA Regional Office for Asia and Pacific (2013) 


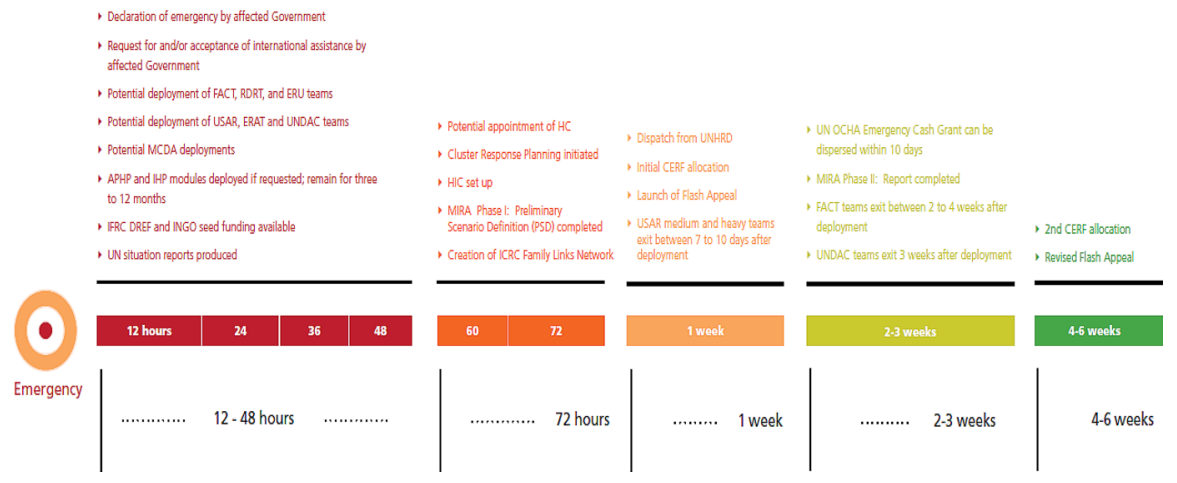

Fig. 1 Timeline of Humanitarian Assistance Tools and Services. Source: OCHA ROAP (2013), Disaster Response in Asia and the Pacific: A Guide to International Tools and Services, p. 31

of the ASEAN region later. For now, a short account is provided of the typical tools and services generally deployed and provided in international humanitarian assistance worldwide.

Given the emergency nature of most situations, the account is best assisted by a time line, as in Fig. 1, which divides the international humanitarian assistance (IHA) process into a number of phases. Within the first 12-48 $\mathrm{h}$ after the sudden onset of a disaster (Phase 1), a declaration of emergency is expected to be made by the government of the affected country, possibly with a request for international assistance, to be followed by the potential deployment of an Emergency Response Unit (ERU), a Regional Disaster Response Team (RDRT), and a Field Assessment Coordination Team (FACT) from IFRC; a Disaster Assessment and Coordination team from UN (UNDAC); and, depending on the need and through due bilateral arrangements, light, medium, and heavy Urban Search and Rescue (USAR) teams from assisting countries. ${ }^{14}$ In the ASEAN region, an ASEAN led regional Emergency Rapid Assessment Team (ERAT) could be dispatched. Similarly, if requested, appropriate modules could be deployed by the International Humanitarian Partnership (IHP) and, regionally, the Asia Pacific Humanitarian Partnership (APHP). While other deployments would terminate soon, these modules could remain for three to 12 months after the occurrence of a disaster. Note that in all the above deployments, Military and Civil Defense Assets (MCDA) could be involved. Emergency seed funding is available from IFRC, namely its Disaster Relief Emergency Fund (DREF), during this phase. A set of UN situation reports are produced at the end of this phase.

The next 24 h (i.e., 48th-72nd hour after the onset of the disaster) constitutes Phase 2, during which UN agencies will lead much of the action. It will see the potential appointment of a Humanitarian Coordinator whose role it is to coordinate all IHA actions, both UN and non-UN (if such a coordinator is not appointed, the UN Resident Coordinator in the disaster affected country will play the coordinating role); the initiation of a UN Cluster Response Planning; the setting up of a Humanitarian Information Center (HIC); the preliminary phase of a Multi-Cluster Initial Rapid Assessment (MIRA); and the completion

\footnotetext{
${ }^{14}$ USAR teams are classified into light, medium and heavy ones depending on the setting under which and difficulties with which urban rescue and search is carried out.
} 
of a Scenario Definition (PSD). During this phase, IFRC could also create a Family Links Network.

Phase 3 is from the end of Phase 2 to within 1 week after the onset of a disaster. This phase can witness the dispatch of various rescue and relief materials from UN Humanitarian Response Depot (UNHRD), the initial funding allocation from the Central Emergency Response Fund (CERF), and the possible launch of new Flash Appeals for funds.

Phase 4 stretches from the second to the third week after the onset of a disaster, and it sees the winding down of much of the rescue and search effort. First, the USAR teams will exit within 7 to 10 days after deployment. FACT teams will exit between 2 and 4 weeks and UNDAC teams 3 weeks after deployment. UN OCHA Emergency Cash Grant may be dispersed within 10 days of the disaster, and the second phase of the MIRA will be completed.

The next 3 weeks still (4th-6th weeks after the onset) make up Phase 5 and the final phase of the IHA process, when the second CERF allocation takes place, accompanied by Revised Flash Appeals, if any.

From this account of a typical IHA process, it may not seem immediately clear how exactly emergency health response is launched and managed following a disaster. On the other hand, presumably this must be a primary component of any rescue and relief work in the immediate aftermath of a disaster-it would be unthinkable that this is not. Emergency health responses are, in fact, built into the very procedures followed and work carried out by the various rescue and relief teams. Local healthcare providers may also mount any effort they can. However, as noted previously, the service capacity of local healthcare providers may have already been severely compromised by the event. But if their resilience level is higher, they may be able to mount some effective rescue and relief operations themselves, and/or to effectively assist the work of outside humanitarian teams. It is likely to be the international teams, rather than the local healthcare providers, that have better expertise and experience in handing a particular situation. On the other hand, local healthcare providers clearly have the advantage of local knowledge and access to any remaining local capability, including the mobilization of local social networks. If the two sides could work closely together, it could dramatically reduce the number of deaths and effectively stem the scale of injury and disease. However, it remains true that in certain especially major disasters, the capacity and capability of local healthcare providers are likely to be so severely compromised that they are unable to play any major role. In these cases, international rescue and relief teams would be the only real option.

Two other salient points appear to emerge from the above account of a typical current IHA process. First, in the immediate aftermath of a disaster-in the first phase of IHA-it is IFRC, and regional and bilateral arrangements, that appear to spearhead the IHA operations, and indeed international emergency health responses. The UN system, including WHO, is very much missing from the picture in this phase. It is not until after Phase 2three entire days after the onset of the disaster-that UN-led operations really kick in. This may be adequate for meeting certain minor emergency needs, but as a mark of the rapidity of international emergency health response, it is clearly not good enough. Within these three days, most of lives that could be saved would be lost; most of the injuries that could be avoided would be sustained. A three-day delay may be alright for controlling the possible spread of diseases as a result of the emergence of new risk factors associated with the disaster, but in overall terms, it is not a good enough mark of emergency health response.

Secondly, it does give one optimism to know that an elaborate set of IHA response mechanisms, involving many actors at various levels, has already been developed and deployed, breaking down the otherwise formidable national boundaries. It indicates that 
real possibilities do exist for developing still more effective international emergency health response mechanisms that would be true to the name.

\section{ASEAN regional humanitarian assistance}

While natural hazards and disasters may visit almost every part of the world, the ASEAN region is probably one of the most prone part. Just over the last two decades, the region has experienced some of the world's most deadly disasters, beginning with the massive earthquake off the coast of Sumatra triggering the deadly Indian Ocean Tsunami in 2004, followed by the Cyclone Nargis in Myanmar in 2008, and the Supertyphoon in the Philippines in 2014. Each of these super events caused tens of thousands of deaths, with even more widespread injuries and diseases, and psychosocial traumas.

The region has also been a hot spot for emerging infectious diseases, including those with pandemic potential. Infectious diseases such as SARS had exacted heavy public health and economic tolls. Likewise, influenza A H5N1 has had a profound effect on the poultry industry in the region. In general, the region is home to some dynamic systems in which biological, social, ecological, and technological processes interconnect in ways that enable microbes to exploit new ecological niches. The regional challenges in the control of emerging infectious diseases are formidable, from influencing the factors that drive disease emergence, to making surveillance systems fit for the purpose, and ensuring that regional governance rise up to the task.

Since the Indian Ocean Tsunami in 2004, the regional block ASEAN has made enormous progress in addressing the needs caused by natural disasters, in particular on the humanitarian assistance front. When ASEAN was first founded in 1967-then with only five Member States, namely Indonesia, Malaysia, the Philippines, Singapore, and Thailand-it had no joint regional programs whatsoever addressing natural disaster risks and disaster management, including emergency responses. The first regional agreement on cooperation in disaster relief - the Declaration for Mutual Assistance on Natural Disasterwas reached in 1976 by the five original Member States. In the next almost three decades, no significant further progress was made in regional cooperation in disaster-related matters except for the re-birth, in 2003, of the ASEAN Committee on Disaster Management (ACDM), a body that had already been in existence in the 1970s. This re-birth, however, saw a strengthening of the organization and mandates of ACDM. Consisting of the heads of the national disaster management organizations (NDMOs) of all ten Member States, the re-born ACDM was to assume the overall responsibility of coordinating and implementing regional disaster management activities among the Member States.

Thereafter came the sudden onset of the Indian Ocean Tsunami on 26 December 2004 with its massive death tolls and widespread devastations. In the wake of this disaster, a flurry of activities took place which culminated in the signing in 2005 of a binding, formal regional agreement by all ten Member States on cooperation in disaster management and emergency response, known as the ASEAN Agreement on Disaster Management and Emergency Response (AADMER). This was subsequently followed by the establishment of the ASEAN Coordinating Centre for Humanitarian Assistance on Disaster Management (AHA Centre) in 2011 - an operational body responsible for monitoring and coordinating all activities envisaged under the AADMER. With this development, both ACDM and AADMER now not only command the authority, but are also equipped with the teeth.

As well as facilitating the cooperation among Member States, the AHA Centre is responsible for cooperating and coordinating with relevant United Nations and other 
international organizations in promoting regional collaboration. It offers a range of tools and functions, including capacity building for Member States' NDMOs, and deployment of emergency response teams.

The ASEAN Disaster Monitoring and Response System (DMRS) and the ASEAN Disaster Information Network (ADInet) are two web-based facilities the AHA Centre has developed and maintained, providing monitoring services and disaster information to the NDMOs of Member States. Additionally, it manages an inter-agency partnership framework, called the AADMER Partnership Group (APG), between ASEAN and several major international NGOs to promote a civil society approach to the implementation of the AADMER.

Not only has ASEAN made huge strides in terms of promoting within-ASEAN regional cooperation in matters of disaster management and response, it has also reached out to 16 other countries and the European Union to form a broad based political and security cooperation platform, the ASEAN Regional Forum (ARF), to foster constructive dialogues on issues of common interest, including disaster management and response. In this latter respect, an especially concrete step was taken by ARF to organize a series of disaster relief exercises (DiREx), typically co-hosted by two countries, one ASEAN Member State and one its ARF partner country. A strong component of the DiREx exercise has been to encourage and refine civilian-military cooperation in disaster relief. The first such exercise was held in 2009.

Within the DiREx exercises, the military assistance included involves foreign military personnel, equipment and facilities. Indeed, establishing clear rules and protocols for the involvement of foreign military assets and personnel in disaster relief and response has been a major concern for ASEAN and the wider Asia-Pacific region. Globally, a process began in 1992 which set out to establish clear rules and protocols for foreign military involvement in disaster situations, under principles of humanity, neutrality, impartiality and sovereignty. This process culminated in a set of non-binding guidelines known as the Oslo MADRO Guidelines (OCHA ROAP 2014). Types of foreign military support envisaged include: air, land and sea survey and assessment; reconnaissance in the disaster zone and of access; search and rescue, evacuation, provision of relief services; engineering; communications; logistics support; and medical support. Given the strong presence of foreign military assets and personnel in the Asia-Pacific region, ASEAN Member States and other countries in the region have an understandable interest in utilizing it, but they also want to ensure that the guidelines are well suited to the conditions in the region. This has led to an initiative to adapt and revise the Oslo Guidelines, resulting in a new set of guidelines, the APC MADRO Guidelines, adopted by the signatory countries in 2009. Indeed, against this background, the series of DiREx exercises organized by ARF can be seen as a continuation of the same initiative.

ASEAN has now developed capabilities close to those commanded by the international players. For example, during the first phase of the IHA process-the first 12-48 $\mathrm{h}$ after the onset of a disaster - the AHA Centre will dispatch its own Emergency Rapid Assessment Team (ERAT). It has also mounted a regional Disaster Relief Fund and a Disaster Emergency Logistic System. As with the international actors, a principal component of the humanitarian assistance provided by ASEAN regional actors to ASEAN Member States must also, first and foremost, be emergency health response.

Most recently in response to the COVID-19 pandemic, although various ASEAN Member States made different policy decisions at the start of the crisis, there has been increasing policy convergence and a more united regional response. During the $26^{\text {th }}$ ASEAN 
Economic Ministers meeting in Viet Nam, ASEAN agreed on a statement "Strengthening ASEAN's Economic Resilience in Response to the Outbreak of the COVID-19," which called for collective action to mitigate the impact of the virus by working with external and development partners. ${ }^{15}$ The statement focused on leveraging technology, digital trade, and trade facilitation platforms such as ASEAN single window, to foster supply chain connectivity and to allow business, especially small- and medium-sized enterprises, to continue operations amidst the pandemic. The statement further addressed the need to improve long-term supply chain resilience and sustainability particularly through the implementation of the Master Plan on ASEAN connectivity (MPAC) 2025.

As a regional block, ASEAN could do still more, indeed a lot more, whether in respect of emergency health or other areas of post-disaster response. However, there can be no denial of the fact that, as a regional bloc, ASEAN has played an especially proactive role in disaster response and has achieved some major progresses, in recent years in protecting the interests and well-being of the populations concerned. It remains for ASEAN to further integrate its fast improving humanitarian assistance track with its larger national health track for each Member State - that is, making the former a key integral part of the latter.

\section{Disaster trends and need for stronger and better coordinated international health response}

This section discusses two additional issues, issues that fell out of the scope of our earlier discussion but nevertheless have a close bearing on the case for building strong international capabilities to ensure hazard resilience of national healthcare systems.

\section{Disaster trends and need for improved health responses especially in poorer countries}

Disaster death tolls appear to have been on the increase in recent decades. Worldwide, a decadal comparison of 1994-2003 with 2004-2013 indicates nearly a threefold increase in the annualized death toll (from around 35,000 in 1994-2003 to 99,700 in 2004-2013, annually) (CRED 2015). Before the current pandemic, the three deadliest mega disasters in the last quarter century all occurred, in fact, in the second decade in the above comparison, namely the 2004 Asian Tsunami with 226,400 deaths, the 2010 Haiti Earthquake with 222,600 deaths, and the 2008 Myanmar Cyclone Nargis with 138,000 deaths. As of August 10, 2020, the current ongoing COVID-19 pandemic has already claimed over 730,000 lives worldwide.

It is not fully clear whether all this signals a general trend of increased frequency of mega disasters, or is merely something coincidental. Whatever it may be, one thing is clear: Mega or major disasters are far from disappearing, but may very frequently visit the mankind. That being so, it is important that each and every country is well prepared against them, of which a central part must be their health preparedness.

While the global picture is already alarming enough, a breakdown analysis of the countries by region and income grouping further underlines the urgency for action. The same CRED (2015) study reports that more natural disaster-related deaths (68\% of the total in

15 https://asean.org/storage/2020/03/AEMR-26-Statement-on-COVID-19-FINAL-10.03.2020.docx.pdf. 
2004-2013) were disproportionately accounted for by poorer countries (low- and lowermiddle-income countries). Furthermore, many of these countries are located in some of the world's most hazard-intensive regions, with Southeast Asia being one of them. With their limited resources but a greater share of the threats, how realistic is it to expect these countries to build, all on their own, an effective, hazard-resilient national healthcare system that would withstand the onslaught of major events, including surviving to meet all the post-disaster emergency health needs? When the question is put in these terms, the answer does seem to be an emphatic "No!".

Yet reduce the number of disaster-related deaths and other human costs of disasters (injuries, diseases and mental-psychological traumas) the poorer countries must, if they are to have a realistic chance of achieving sustained socioeconomic progress and improved well-being. Besides causing immense immediate sufferings to their populations, natural disasters have too often inflicted huge damages to the economies of these countries. By stripping these countries of their critical human capital, and key physical infrastructures and other assets, natural disasters undercut these countries' otherwise robust chance of socioeconomic progress. While they may in the short term raise the level of economic activity (GDP) of an affected country, natural disasters almost always reduce that country's long-term developmental potential (Cavallo et al. 2010; Baez et al. 2010).

For these reasons, an important objective of a country's disaster preparedness program must be to reduce the scale of deaths and injuries and other kinds of human sufferings of a disaster. To this end, an adequate health response system, to be mobilized and set into action immediately after a disaster has struck, ought to be one of the most important components of a country's disaster preparedness program. This study points to ways of building a hazard-resilient national health system for countries that lack the resources and/ or economic scale, ${ }^{16}$ by explicitly incorporating and factoring in international capabilities. There does seem an overwhelming case for the global community to act, by organizing and building such international capabilities ready for deployment wherever and whenever a major disaster strikes anywhere in the world.

\section{Stronger and better coordinated international health response}

As explained in this paper, depending on the need, international capabilities may be organized and developed regionally or globally, and they do not even have to be a long-standing force. Most of the actual capabilities for rapid deployment can be personnel and staff from existing healthcare systems of the participating countries, with regular trainings and exercises. However, a minimum level of personnel would be needed to staff as much as possible a slim top-down organizational structure for continuously monitoring changing hazard

\footnotetext{
16 The need of a country for international assistance in post-disaster health response will depend on both its resources and scale. If "resources" are measured in terms of per capita income, clearly the richer a country is, the better it is positioned to respond to the health impact of a disaster. However, per capita availability of resources is not the only thing that matter. If the threat is large in scope, both geographically and population-wise, mere high per capita availability of resources would not necessarily enable a country to respond to the threat successfully. The scale of a country also matters. A larger scale could allow for a much higher level of cross-jurisdictional (i.e., across political and other jurisdictions within a country) mobilization of resources in a way that a smaller-scale country could not. Earlier in 2020, such cross-jurisdictional mobilization of resources (doctors, other health professionals, and otherwise) played a key role in Chinese government's ability to stamp out the COVID-19 outbreak in Wuhan, which made possible the country's overall success in the fight against the pandemic.
} 
and disaster situations in the region or globe, and to ensure rapid decision making, and mobilization and dispatch of the capabilities if an event occurs,

This would represent a sharp contrast to the current international architecture for postdisaster international health response. As detailed at some length in Sect. 5, the UN-led health response is not kicked in until three whole days after the onset of a disaster. In these first three days, it is the IFRC that fills the role. While being a formidable international capability with a long history of providing crucial post-disaster health responses worldwide, IFRC has clearly been shouldering tasks that are beyond its reach and capacity, and resources. Although in recent years other NGO- and civil society organization-led initiatives have appeared on the scene, ultimately there remains a strong need not only for effective professional rescue capabilities but also for more timely and effective coordination between various actors. Indeed, some level of "centralization" is necessary here. Where minutes matter to lives saved and lost, the need for effective coordination and centralization is clear. A stand-by international professional health response capacity would make possible rapid decision making, and enable a rapid response command structure to be erected, as well as providing the substantive capabilities that are needed. ${ }^{17}$

While decentralized responses through the initiatives of various national and international civil society organizations are clearly an important component for constructing an overall international capability to mount the much needed timely and effective rescue and relief operations in a region or globally, it does not seem they can be the sole pillar to the whole architecture. This paper argues that there needs to be another pillar, a stand-by professional international capability with a rapid decision making and rapid response command structure. The aforementioned decentralized initiatives and processes will need to be complemented by a centralized structure to make timely and effective international postdisaster health responses a reality. In the parlance of the supply chain, this rapid decision making and response structure plays the equivalent role of a "lead" firm, while all the other actors act as the "service nodes" or "distributional linkages" in the chain. It is hoped that the arguments set forth in this study can help step up further research in this critical area of life and death, as well as expand the scope of supply chain-related research.

\section{Conclusion}

This paper has applied a supply chain approach to develop the concept of a hazard-resilient healthcare system (HRHS) and explored ways how this might be achieved. The current international thinking on HRHS has narrowly focused on building national capacities and national capabilities. The present paper argues that a supply chain approach may provide a better, more robust, and in many ways more realistic approach to promote the hazard

\footnotetext{
17 The case of the not-too-recent Haiti Earthquake health response underlines the need for effective coordination between different actors, most of which were international civil society organizations. These actors had sent in medicines, equipment, rescue teams, and even full units of field hospital. However, without effective and close coordination, and without much professional expertise in handling rescue and relief matters, some of these actors failed to make any significant contribution to the rescue and relief effort. In certain cases, the contribution was even negative (de Goyet et al. 2011). Following the Haiti Earthquake debacle, WHO felt a need to regulate future "foreign medical teams," and introduced a process of "classification, standards, registration, quality, accreditation and accountability" (WHO 2013), but has otherwise continued to champion such "decentralization." However, it does not seem likely that the new rules can fundamentally rectify the situation (Gerdin et al. 2012).
} 
resilience of national healthcare systems. Within such an approach, capabilities of the local actors (local health authorities and healthcare providers) in a pandemic or disaster situation remain important and should be further strengthened, but international support and assistance in terms of real capabilities in times of emergency, especially when it is a major one, will have to be a key plank of the system. In a changing world perhaps with more frequent high-impact pandemics and disasters, such international support need not be one way, but both ways. A system of mutual support can be formed by developing an effective, highly coordinated international common pool of health capabilities ready for deployment any time when a major disaster occurs somewhere in the world. Even though serious limitations exist in the current thinking on HRHS, significant progress has been made on the international humanitarian assistance front, especially in the ASEAN region. While developments on this front have not been a part of the purview of the current international thinking on HRHS, it is argued that they may well form an important corner stone in a typical future national HRHS.

\section{References}

Anbumozhi V, Kimura F (2020) Regional frameworks for advancing supply chain resilience and business continuity plans. In: Anbumozhi V, Kimura F, Tahngavel S (eds) Supply Chain Resilience: reducing vulnerability to economic shocks, financial crisis and natural disasters. Springer, Berlin, pp 307-338

Anbumozhi V, Kimura F, Thangavelu S (2020) Global supply chain resilience: vulnerability and shifting risk management strategies. In: Anbumozhi V, Kimura F, Tahngavel S (eds) Supply chain resilience: reducing vulnerability to economic shocks, financial crisis and natural disasters. Springer, Berlin, pp 3-17

Baez, Javier, Alejandro de la Fuente and Indhira Santos (2010) Do Natural Disasters Affect Human Capital? An Assessment Based on Existing Empirical Data. IZA Discussion Paper No. 5164

Bennett B, Carney T (2017) Public health emergencies of international concern: global, regional and local responses to risk. Med Law Rev 25(2):223-239

Brenna R (2015) Reducing disaster risk for better health [Online]. https://www.devex.com/news/reducingdisaster-risk-for-better-health-85682. Accessed: December 21, 2015

Cavallo, Eduardo, Sebastián Galiani, Ilan Noy and Juan Pantano (2010) Catastrophic Natural Disasters and Economic Growth. IDB Working Paper Series No. IDB-WP-183

Centre for Research on the Epidemiology of Disasters (CRED) (2015) The Human Cost of Natural Disasters 2015: A Global Perspective. CRED, Brussels

de Goyet, Claude de Ville, Juan Pablo Sarmiento and Francois Grunewald (2011) Health Response to the Earthquake in Haiti, January 2010: lessons to be learned for the next massive sudden-onset disaster. Pan American Health Organization (PAHO)

Gerdin M, Wladis A, Von Schreeb J (2012) Foreign field hospitals after the 2010 Haiti earthquake: how good were we? Emergency Medicine Journal [Online], 7 March 2012

Liu M (2016) Hazard-Resilient Health Services: A supply chain approach, report submitted to Economic Research Institute for ASEAN and East Asia (ERIA)

Liu M, Wang Q (2020) International capabilities and national hazard resilient healthcare systems: future directions for Chinese health aid. Social Sci J 2020(3):175-183 (In Chinese.)

Mitchell T, Jones L, Lovell E, Comba E (eds) (2013) Disaster risk management in post-2015 development goals: potential targets and indicators. Overseas Development Institute, London

OCHA Regional Office for Asia and Pacific (2013) Disaster Response in Asia and the Pacific: A Guide to International Tools and Services. OCHA Regional Office for Asia and Pacific, Bangkok

OCHA Regional Office for Asia and Pacific (2014) Asia-Pacific Regional Guidelines For The Use Of Foreign Military Assets In Natural Disaster Response Operations Version 8.01. Bangkok: OCHA Regional Office for Asia and Pacific

Tschoegl L, Below R, Guha-Sapir D (2006) An Analytical Review of Selected Data Sets on Natural Disasters and Impacts. UNDP/CRED Workshop on Improving Compilation of Reliable Data on Disaster Occurrence and Impact, April 2-4, 2006, Bangkok 
UNISDR (2006) Hyogo framework for action 2005-2015: building the resilience of nations and communities to disasters. UNISDR, Geneva

UNISDR (2015) Sendai framework for disaster risk reduction 2015-2030. UNISDR, Geneva

Wang L (2018) Research on Risk Management for Healthcare Supply Chain in Hospital, Doctoral Thesis, Liverpool John Moores University

WHO (2005) International Health Regulations, 2nd edn. WHO, Geneva

WHO (2008) Global assessment of national health sector emergency preparedness and response. WHO, Geneva

WHO (2011), Strengthening national health emergency and disaster management capacities and resilience of health systems. Sixty-Fourth World Health Assembly Agenda item 13.4, 24 May 2011

WHO (2013) Registration and coordination of Foreign Medical Teams responding to sudden onset disasters: The way forward. WHO Foreign Medical Team Working Group, Geneva

WHO (2020) 73rd World Health Assembly Covid-19 Response Agenda, WHA 73.1 https://apps.who.int/gb/ ebwha/pdf_files/WHA73/A73_R1-en.pdf

WHO and Pan American Health Organization (2015) Safe Hospital Index: Guide for Evaluators. WHO, Geneva

WHO and UK Health Protection Agency and Partner (2011), Safe Hospitals: Prepared for Emergencies and Disasters. Disaster Risk Management for Health Fact Sheets, Global Platform, May 2011

WHO, UNAIDS, UNFPA, UNICEF and UNISDR (2015) Protecting People's Health from the Risks of Disasters. WHO, Geneva

Publisher's Note Springer Nature remains neutral with regard to jurisdictional claims in published maps and institutional affiliations.

\section{Affiliations}

\section{Minquan Liu $^{1} \cdot$ Venkatachalam Anbumozhi ${ }^{2}$}

1 School of Economics and Center for Human and Economic Development Studies, Peking University, Beijing, People's Republic of China

2 Economic Research Institute for ASEAN and East Asia (ERIA), Jakarta, Indonesia 